American Journal of Environmental Sciences 5 (4): 487-493, 2009

ISSN 1553-345X

(C) 2009 Science Publications

\title{
Pore Water Pressure Contribution to Debris Flow Mobility
}

\author{
Chiara Deangeli \\ DITAG-Department of Land, Environment and Geo-Engineering, \\ Politecnico di Torino, Corso Duca Degli Abruzzi 24, 10129 Torino, Italy
}

\begin{abstract}
Problem statement: Debris flows are very to extremely rapid flows of saturated granular soils. Two main types of debris flow are generally recognized: Open slope debris flows and channelized debris flows. The former is the results of some form of slope failures, the latter can develop along preexisting stream courses by the mobilization of previously deposited debris blanket. The problem to be addressed is the influence of the mode of initiation on the subsequent mechanism of propagation. In particular the role of pore water pressure on debris flow mobility in both types was debated. Approach: Laboratory flume experiments were set up in order to analyze the behavior of debris flows generated by model sand slope failures. Failures were induced in sand slopes by raising the water level by seepage from a drain located at the top end of the flume, and by rainfall supplied by a set of pierced plastic pipes placed above the flume. Video recordings of the tests were performed to analyze debris flow characteristics. Results: In all the tests the sand water mixture flows were unsteady and non uniform and sand deposition along the channel bed was a relevant phenomenon. The flows were characterized by a behavioral stratification of the sand water mixture along the flow depth. Back analyzed pore water pressure were just in excess to the hydrostatic condition. The reliability of the experimental results was checked by comparison with other flume experiment data. Conclusion: Debris flow behavior was influenced by the mode of initiation, the inclination of the channel and grain size of the soils. These factors affected the attained velocities and the pore water pressure values. The mobility of debris flows was not always enhanced by high excess pore water pressure values.
\end{abstract}

Key words: Debris flows, flume experiments, pore water pressure

\section{INTRODUCTION}

Debris flows are natural phenomena characterized by great volumes of concentrated mixtures of water and sediments. They develop in mountainous areas with high velocities and are triggered by unusual presence of water.

Intense rainfall of short duration is the major factor affecting their occurrence; this feature in conjunction with celerity of propagation of the phenomenon leads to define debris flows as instantaneous processes.

For these reasons debris flows can be considered among the most destructive natural processes, causing fatalities, structure damage and loss of productivity of an area.

Two main type of debris flows are generally recognized: Channelized debris flows that occur in preexisting stream courses, hill slope debris flows that are the result of slope failures.

By a general point of view this class of natural phenomena is included in the subject of concentrated suspensions. The solid phase is composed by soils ranging from gravel to clay size in various proportions, with the frequent presence of pebbles and big boulders.
Rheological behavior of concentrated suspensions has been faced by three, apparently distinct, fields, which consider different types of material under various conditions: Rheology of suspensions; physics of granular matter; geo-techniques.

Campbell ${ }^{[1]}$ observed that granular flows are very complex systems and the most basic flow mechanisms of granular material are not well understood, because the set of material properties that control the flow behavior have not been identified.

Because of the complexity of the system and the high velocities, the study of debris flows is frequently approached by instrumented laboratory flume experiments.

Two main kinds of flume experiments are generally performed:

- Debris flows generated by slope failures ${ }^{[2-5]}$

- Debris flows obtained by direct discharge of a mixture of solid particles and water along the channel or by water discharge on a debris bed ${ }^{[6-14]}$ 
The first type of flume experiments are in general devoted to the investigation of the pore water pressure increase within the soil slope mass from the saturation until the slope failure and the immediate post failure phase.

The second type of flume experiments usually analyzes the rheological features of the suspension. However Armanini and Gregoretti ${ }^{[12]}$, investigated the triggering of debris flows by erosion mechanism, and Spence and Guymer ${ }^{[9]}$, Iverson ${ }^{[10]}$ and Okada and Ochiai ${ }^{[13]}$ performed pore water pressure measurements during the flow phase along the flume.

The behavior of debris flows, generated by slope failures, is marginally investigated.

The research reports the results of flume experiments performed to analyze the propagation of debris flows, generated by model sand slope failures by increasing the water content of the soil. Finally a comparison between other flume experiments conducted in similar conditions is presented, highlighting the role of pore water pressure in different test conditions and the combination of factors influencing the different types of observed debris flow behaviors.

\section{MATERIALS AND METHODS}

The experimental apparatus is constituted by a flume $7 \mathrm{~m}$ long, $1 \mathrm{~m}$ wide and $0,5 \mathrm{~m}$ deep, that can tilt from $0^{\circ}$ up to $18^{\circ}$ (Fig. 1). Lateral glass walls allow the observation of the failure of the slope and the propagation of the flow. The flume is connected downwards to a horizontal tank $2 \mathrm{~m}$ long, $2 \mathrm{~m}$ wide and $0,5 \mathrm{~m}$ deep. The wood floor of the channel is covered by an impervious cloth with glued angular coarse sand particles.

Movements of the material during experiments were recorded using two movie cameras operating at 500 frames $\mathrm{sec}^{-1}$, installed at $2 \mathrm{~m}$ and $4 \mathrm{~m}$ from the top end of the flume. A video camera operating at 64 frames $\sec ^{-1}$ was positioned in order to record movements by a frontal point of view. Furthermore a camera providing photographs every $0,25 \mathrm{~s}$ with an enlargement of 7 times was installed at a location of $4 \mathrm{~m}$ in order to observe particle settling.

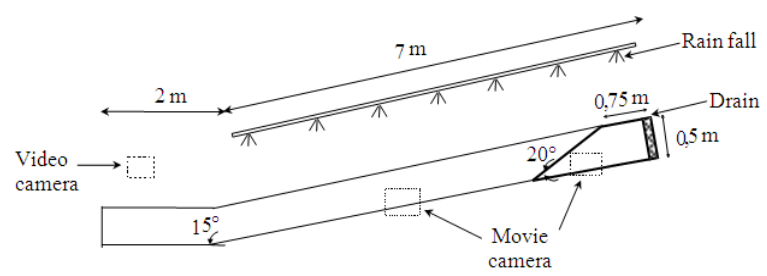

Fig. 1: Arrangement of experimental apparatus
A medium fine silica sand, with a repose angle of $32^{\circ}$, was used as the test material. The physical properties of the sand are reported in Fig. 2 and Table 1.

Sand was placed in dry conditions in a series of horizontal layers using a traveling hopper, by maintaining the flume in horizontal position. A soft compaction was applied on the deposited sand in order to obtain the required density of the material. The density index ranged from 0,30-0,40. In all the experiments the total volume of the sand slope was about $0,725 \mathrm{~m}^{3}$.

The dry sand slope was built up with an inclination of $20^{\circ}$ and the flume was tilted at $15^{\circ}$, with an overall inclination of 35 . After the phase of deposition the sand was wetted and then the flume was tilted to the required angle. The configuration of the slope is reported in Fig. 1.

Instability was induced in sand slopes by raising the water level by seepage from a drain located at the top end of the flume and by rainfall supplied by a set of pierced plastic pipes placed above the flume.

The drain is constituted by coarse sand-filled wire cage with a constant head tank supplying water. An uniformly distribution of rainfall along the pipes was ensured by keeping the water pressure constant and by mixing the water with pressured air. In all tests the rainfall intensity was $1,7 \mathrm{~mm} \mathrm{~min}^{-1}$.

Table 1: Properties of the sand used as test material

\begin{tabular}{ll}
\hline Solid density $\left(\mathrm{Mg} \mathrm{m}^{-3}\right)$ & 2,66 \\
Maximum dry density $\left(\mathrm{Mg} \mathrm{m}^{-3}\right)$ & 1,69 \\
Minimum dry density $\left(\mathrm{Mg} \mathrm{m}^{-3}\right)$ & 1,38 \\
Minimum void ratio & 0,57 \\
Maximum void ratio & 0,92 \\
Maximum concentration & 0,64 \\
Minimum concentration & 0,52 \\
$\mathrm{D}_{50}$ & 0,32 \\
$\mathrm{D}_{10}$ & 0,20 \\
$\mathrm{U}$ uniformity coefficient & 1,9 \\
\hline
\end{tabular}

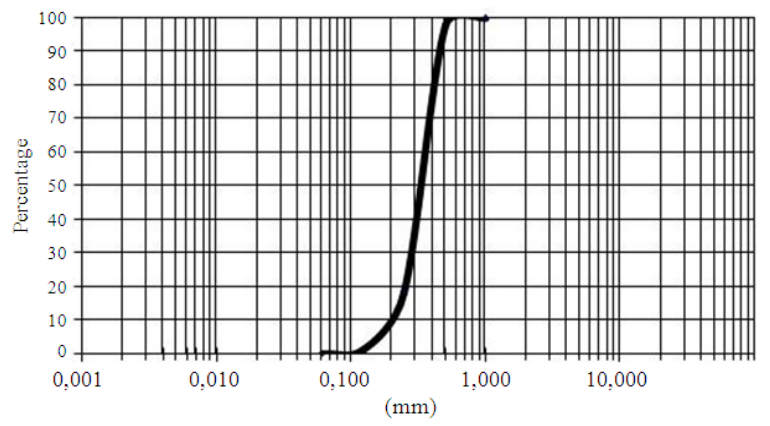

Fig. 2: Grain size distribution of the sand used as test material 


\section{RESULTS}

The instability of sand slopes occurred by retrogressive multiple slides starting at the toe and characterized by a downwards rapid acceleration of the unstable slice followed by a deceleration of the sand. The subsequent flow of the water sand mixture was induced by the additional water supplied by the rainfall, on the collapsed material and seemed to be independent of the initial density index in the investigated range of values.

The first surge of flowing sand water mixture was characterized by a surficial velocity of $0,3 \mathrm{~m} \mathrm{sec}^{-1}$.

In all the examined cases the sand water mixture flow was generally unsteady (decelerating) and non uniform and for a few seconds only it was possible to observe constant behavior of the flow.

The observations performed during the experiments show that settling of sand particles was a relevant process during the flow motion. This demonstrated that at a certain time the velocity of solid particles differed substantially from the velocity of flowing water.

The observation of the video recordings allowed the analysis of the phenomenon after the slope failure at a location $2 \mathrm{~m}$ far from the source area. The process was characterized by a first surge of flowing sand water mixture, followed by a deceleration of the motion resulting in a transformation of the movements from flow to sliding, until the complete stoppage. In this stage of the process the mass was composed by three layers behaving in different manners and moving at different velocities (from the bottom of the flume): The first layer was static, the second slid and the third flowed. Fig. 3a) and b) reports the typical behavior of the sand water mixture, measured in two experiments.

A second stage of the process seemed to starts (Fig. 3), showing a behavior like the previous stage, but characterized by a small increase of thickness of the flowing layer during time, followed by sliding and stoppage of the sand.

The role of pore water pressure was indirectly investigated by back analyzing the travel distance of the sand water mixture, by using the sliding consolidation model of Hutchinson ${ }^{[14]}$. In this model a frictional term, coupled with an one-dimensional consolidation algorithm, predicts the gradual dissipation of excess pore water pressure in a soil element after shear failure. The results of back analyses ${ }^{[5]}$ (Fig. 4) showed that pore water pressures were in excess to the hydrostatic values but smaller than the maximum values (liquefaction of the soil).

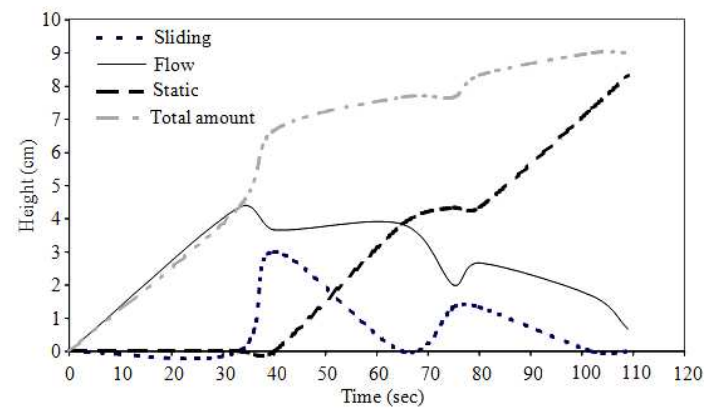

(a)

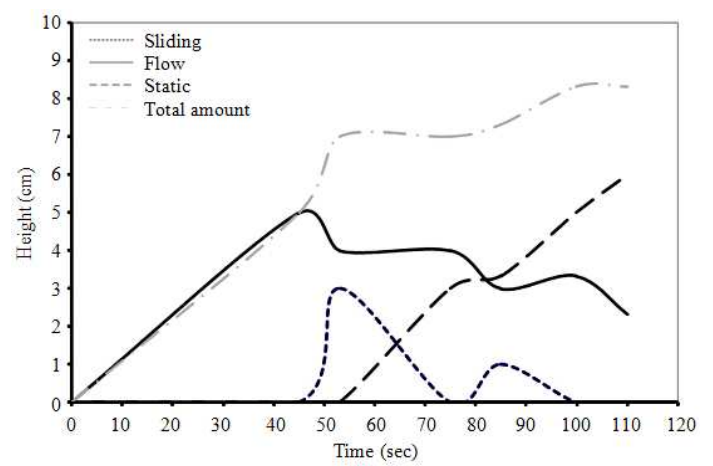

(b)

Fig. 3: Development of sand water mixture layers recorded by the movie camera. a) flume experiment $2 \mathrm{~B}$; b) flume experiment $4 \mathrm{~B}$.

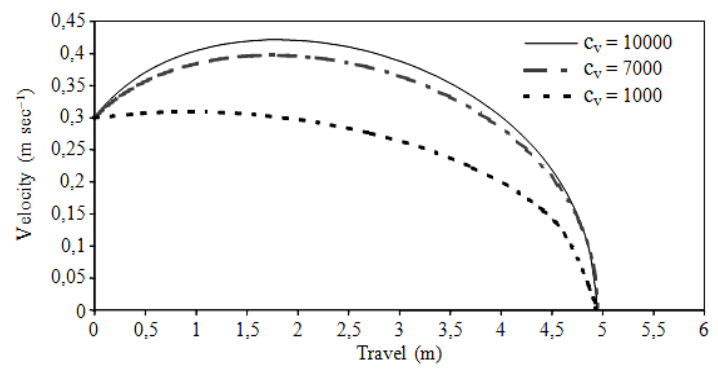

Fig. 4: Results of the computations of flume tests performed with the sliding consolidation model ${ }^{[14]}$, for different values of $c_{v}$ (the values reported in the legend are $\mathrm{m}^{2}$ year $\left.^{-1}\right)^{[5]}$

The movement of sand water mixture, as a phenomenon generated by the retrogressive failures of the sand slope and transformed into flow by the additional amount of water supplied by rainfall, ceased due to exhaustion of collapsing sand from the slope. A sudden change of the cause of occurrence of sand water mixture flow happened: in fact the water supplied by rainfall overflowed the sand deposited along the flume, causing erosion, with a consequent thinning of the static 
layer. This process was very rapid and the flow seemed to show a lower solid concentration.

All the collapsed material experienced the three types of behavior in subsequent periods. The deposited thickness of sand (excluding erosion) along the flume resulted near constant in all the experiments. A relevant part of the sand forming the original slope did not take part to the flow phase and remained deposited in the upper part of the flume.

\section{DISCUSSION}

The results of flume experiments reported in the previous section show that debris flows generated by slope failures are characterized by a great variability of the velocity along the flow depth, and by the deposition of the solid phase. As a consequence, the back analyzed excess pore pressures are lower than the values required for liquefaction of the sand. In order to check the reliability of the obtained results a comparison between some other flume experiments, has been performed.

It is worth to mention that the results of flume experiments carried out by triggering debris flows by water discharges on sediment beds constituted by sand or gravel, show rapid fully developed flows characterized by high solid contents also when channel inclinations are low ${ }^{[6,7]}$ as in the reported experimental data.

Flume experiments conducted with the purpose of investigate flow failure behavior in soil model slopes ${ }^{[2-4]}$ are perhaps more similar to the performed flume experiments.

For instance Wang and Sassa ${ }^{[4]}$ measured rapid increase of pore pressure (in excess to the hydrostatic value) just after major failure followed by a rapid decrease. The authors argued up that two reasons can explain this trend: Decrease in height of the failed soil mass and dissipation of pore water pressure. They also observed a successive slow movement of the collapsed soil after the major failure with continuing of sprinkling of water. These last observations are consistent with the findings presented in this study. Unfortunately Wang and Sassa ${ }^{[4]}$ did not measure pore pressure during this stage.

Debris flows initiated by rapid removal of a water proof barrier ${ }^{[9,10,13]}$ show different behaviors and different pore pressure patterns.

Spence and Guymer ${ }^{[9]}$ in their flume experiments observed a deceleration of the flow and unsteady deposition of the sand along the flume. Measured pore pressure was just in excess to the hydrostatic condition and comparable to the value necessary to maintain equilibrium between driving and resisting forces. The back analyzed pore water pressure values with the Hutchinson model ${ }^{[14]}$ are in agreement with these measurements.

Flume experiments, carried out by Iverson ${ }^{[10]}$, show a delayed response of pore pressure measurements with respect to flow depth and total stress measurements, with pore pressures sometimes greater than the total stresses during both the flow phase and the deposition phase.

The results of flume experiments performed by Okada and Ochiai ${ }^{[13]}$ show that excess pore water pressure was generated only when fine material was present in the suspension. They argued up that high pore fluid pressure is likely to be a product of both: Increased pore fluid density due to suspended particles and the quasi-undrained shear deformation of the granular mass. The measured excess pore water pressure peaked at the measurement point very close to the water proof gate and assumed a lower value in the other measurements points, located at greater distance. Debris flows composed exclusively by gravel water mixtures were characterized by pore water pressure smaller than the hydrostatic value, indicating that the material was not fully saturated during the flow phase.

On the basis of the previous reported results the rise of pore water pressure (in excess to the hydrostatic value) in debris flows do not appear to be a prerequisite to enhance their mobility. At least two different types of debris flow, characterized by different mechanisms of propagation, seem to occur.

A more detailed analysis of the results of flume experiments ${ }^{[4,5,9,13]}$ is therefore required in order to identify the thresholds between the observed types of debris flow behavior.

For this purpose it is necessary to select some parameters in order to investigate their roles in the propagation phase. The selection of parameters has been performed on the basis of the following considerations:

- Theoretical and experimental studies on the rheology of suspensions indicate that saturated granular flows, composed exclusively by coarse particles, show a frictional behavior and collisional behavior under slow and rapid deformations respectively ${ }^{[11]}$. The transition between frictional and collisional behavior appears controlled by viscous effects

- By a geotechnical point of view the occurrence of flow like movements in granular soils is dependent on the undrained behavior of the soil and on its susceptibility to liquefaction. The term liquefaction is frequently used to indicate all phenomena involving excessive deformation in saturated 
cohesionless soils and is not limited to the development of $100 \%$ excess pore pressure. Liquefaction due to static loading is associated with granular soils deforming in a strain softening (or limited strain softening) manner that results in limited or unlimited unidirectional flow deformation $^{[15]}$. Results of undrained triaxial compression test indicate that two main factors control the development of positive excess pore pressure in granular soils: The initial void ratio and the presence of fine soils. The applied state of stress also influences the behavior of the soil samples

- The flow regimes and the development of layers along the depth of the flow is influenced by the inclination of the channel ${ }^{[11]}$

Table 2 and 3 report in details the selected parameters of the above mentioned flume experiments.

The comparison among the results of the experimental data shows that the flow behavior is very complex and is ruled by a combination of factors.

The major contribution to debris flow behavior seems to be the inclination of the channel. From the available data an inclination in excess of $15^{\circ}$ appears to be the threshold for fully developed debris flows, independently from the grain size of the soil and type of triggering.
Grain size distribution strongly influences the development of positive excess pore water pressure. On the basis of investigated data, the greater increase of pore water pressure occurs in presence of fine soils (grain size $<0,074 \mathrm{~mm}$ ), with a percentage of about $10 \%$ by weight.

In fine soils pore water pressures reach lower values with the lower inclinations.

The initial void ratio affects the pore water pressure increase, but is irrelevant at large grain sizes if the grain size distribution is uniform.

The mode of initiation of debris flow shows a great influence on the attained velocities and pore pressure values.

Maximum pore water pressure values are measured near the water proof barrier, lower values are measured in the other locations. This behavior indicates the dynamic effect of the vertical fall of the mixture after the removal of the barrier, resulting in dynamic overpressure contribution. Lower values measured far from the barrier indicate that dissipation occurs.

As no pore water pressure measurements during the flow phase are available in the case of debris flows generated by slope failures, some doubts remain concerning the self generation of excess pore water pressure along the path as a result of fast volumetric compressions.

Table 2: Flume experiment data

\begin{tabular}{|c|c|c|c|c|c|c|c|}
\hline \multirow[b]{2}{*}{ Flume experiments } & \multirow[b]{2}{*}{ Sample } & \multicolumn{3}{|l|}{ Grain size } & \multirow[b]{2}{*}{$\begin{array}{l}\text { Initial void } \\
\text { ratio }\end{array}$} & \multirow[b]{2}{*}{$\begin{array}{l}\text { Channel } \\
\text { inclination }\end{array}$} & \multirow[b]{2}{*}{$\begin{array}{l}\text { Slope } \\
\text { inclination }\end{array}$} \\
\hline & & $\mathrm{D}_{50}(\mathrm{~mm})$ & $\mathrm{D}_{10}(\mathrm{~mm})$ & $\mathrm{U}$ & & & \\
\hline Deangeli $^{[5]}$ & SSD: Silica Sand & 0,32 & 0,20 & 1,9 & $0,78-0,82$ & $15^{\circ}$ & $20^{\circ}$ \\
\hline Okada and Ochiai ${ }^{[13]}$ & S1: Pumiceous gravel & 30 & 12 & 2,9 & $4,8-4,6$ & $30^{\circ}$ & - \\
\hline Okada and Ochiai ${ }^{[13]}$ & $\mathrm{S} 2: \mathrm{S} 1+$ Volcanic ash & 0,32 & 0,07 & 1,9 & $0,92-0,95$ & $30^{\circ}$ & - \\
\hline Wang and Sassa ${ }^{[4]}$ & S7: Silica Sand n.7 & 0,13 & 0,074 & 2,1 & $0,97-1,50$ & $30^{\circ}$ & $15^{\circ}$ \\
\hline Wang and Sassa ${ }^{[4]}$ & S8: Silica Sand n.8 & 0,05 & 0,018 & 3,7 & $1,29-1,77$ & $30^{\circ}$ & $15^{\circ}$ \\
\hline Wang and Sassa ${ }^{[4]}$ & M10: S8 + $10 \%$ loess & 0,047 & 0,0118 & 4,6 & 1,61 & $30^{\circ}$ & $15^{\circ}$ \\
\hline Wang and Sassa ${ }^{[4]}$ & M20: S8 + 20\% loess & 0,043 & 0,0084 & 6,0 & 1,5 & $30^{\circ}$ & $15^{\circ}$ \\
\hline Wang and Sassa ${ }^{[4]}$ & M30: S8 + 30\% loess & 0,040 & 0,0057 & 8,3 & 1,58 & $30^{\circ}$ & $15^{\circ}$ \\
\hline Spence and Guymer ${ }^{[9]}$ & LBS: Leighton Buzzard Sand & 0,080 & 0,0500 & 1,8 & $0,89-1,07$ & $0^{\circ} 6^{\circ} 9^{\circ} 12^{\circ}$ & - \\
\hline
\end{tabular}

Table 3: Additional flume experiment features (excess pore water pressure: + present; ++ high; +++ very high)

\begin{tabular}{lllll}
\hline Sample & Type of initiation & Pore water pressure & Excess pore \\
SSD & Slope failure & Back analyzed during the flow & Positive + & Flow features \\
S1 & Barrier removal & Measured during the flow & Negative & Sand deposition along the channel \\
S2 & Barrier removal & Measured during the flow & Positive +++ & Very rapid flow \\
S7 & Slope failure & Measured until major failure & Positive ++ & Slow flow (other information not available) \\
S8 & Slope failure & Measured until major failure & Positive +++ & Slow flow (other information not available) \\
M10 & Slope failure & Measured until major failure & Positive ++ & Slow flow (other information not available) \\
M20 & Slope failure & Measured until major failure & Positive ++ & Slow flow (other information not available) \\
M30 & Slope failure & Measured until major failure & Positive ++ & Slow flow (other information not available) \\
LBS & Barrier removal & Measured during the flow & Positive + & Decelerating flow \\
& & & & Sand deposition along the channel
\end{tabular}


The surficial velocity of the debris flows appears to be dependent on the channel inclination and the mode of initiation. The correlation between velocity and pore water pressure is not so evident: Okada and Ochiai ${ }^{[13]}$ observed that although the greater pore water pressure that occurred in S2 was expected to generate higher down slope velocity, it flowed rather slowly in fact.

Fully developed debris flows can propagate without positive pore pressures at very high velocities.

The development of high positive excess pore pressures during debris flow propagation seems to depend on fine soil contents, channel inclinations and modes of initiation and in minor extent on initial void ratios.

\section{CONCLUSION}

Laboratory flume experiments were performed to investigate the behavior of debris flows generated by slope failures.

The results of laboratory measurements showed that debris flows were unsteady and a behavioral stratification of the soil water mixture along the flow depth occurred.

The flows were characterized by unsteady deposition of the sand and the re-transformation of the movement from flow to sliding until the stoppage of the sand.

Pore water pressures were back analyzed on the basis of the sliding consolidation model ${ }^{[14]}$, by imposing the measured displacements. The obtained values were just in excess to the hydrostatic conditions and according to Spence and Guymer findings ${ }^{[9]}$ were closest to a value predicted by assuming equilibrium of driving and resisting forces.

The comparison of these results with data reported by other authors based on flume experiments set up in different conditions has enabled to identify the role of some factors on debris flow behavior and implications for future study:

- The major contribution to debris flow behavior appears to be the inclination of the channel. An inclination in excess of $15^{\circ}$ seems to be the threshold for fully developed debris flows, independently from the grain size of the soil and type of initiation

- The mode of initiation of debris flows affects both velocities and pore water pressures during the flow phase. The correlation between velocity and pore water pressure is not so evident: debris flows can propagate without positive pore water pressures at very high velocities
- Debris flows generated by the sudden removal of a water proof barrier exhibit pore water pressures in excess to the hydrostatic condition, with the maximum value measured near the barrier: the dynamic overpressure contribution, induced by the fall of the mixture, should be further investigated

\section{ACKNOWLEDGMENT}

This research is financially supported by MIUR (Ministry of the University and Research), in the framework PRIN 2007, "Assessment of debris flow hazard in different geological and climatic conditions", Research Partner: Politecnico di Torino.

\section{REFERENCES}

1. Campbell, C., 2006. Granular material flows-An overview. Powder Technol., 162: 208-229. http://cat.inist.fr/?aModele $=$ afficheN\&cpsidt $=1761$ 4696

2. Eckersely, D., 1990. Instrumented laboratory flowslides. Géotechnique, 40: 489-502. http://md1.csa.com/partners/viewrecord.php?reque ster $=$ gs\&collection=TRD\&recid=9013929AN\&q=I nstrumented+laboratory+flowslides\&uid=7871993 $05 \&$ setcookie $=$ yes

3. Wang, G. and K. Sassa, 2001. Factors affecting rainfall-induced landslides in laboratory flume tests. Géotechnique, 51: 587-599. http://cat.inist.fr/?aModele $=$ afficheN\&cpsidt $=1138$ 735

4. Wang, G. and K. Sassa, 2003. Pore pressure generation and movement of rainfall induced landslides: Effects of grain size and fine particle content. Eng. Geol., 69: 109-125. http://cat.inist.fr/?aModele=afficheN\&cpsidt $=1466$ 1715

5. Deangeli, C., 2008. Laboratory granular flows generated by slope failures. Rock Mech. Rock Eng., $\quad 41$ : 199-217. http://cat.inist.fr/?aModele $=$ afficheN \&cpsidt $=2042$ 0157

6. Takahashi, T., 1991. Debris Flow. IAHR Monograph, Balkema, Rotterdam.

7. Lanzoni, S. and M. Tubino, 1993. Rheometric experiments on mature debris flow. Proceedings of the Congress International Association for Hydraulic Research, (IAHR'93), Local Organizing Committee of the XXV Congress, Netherlands, pp: 47-47.

http://direct.bl.uk/bld/PlaceOrder.do?UIN=015724 $341 \&$ ETOC $=\mathrm{EN} \&$ from $=$ searchengine 
8. Winterwerp, J.C., M.B. de Groot, D.R. Mastbergen and H. Verwoert, 1990 Hyperconcentrated sand water mixture flows over flat bed. J. Hydraul. Eng. 116: 36-52.

http://cat.inist.fr/?aModele $=$ afficheN\&cpsidt $=6673$ 110

9. Spence, K.J. and I. Guymer, 1997. Small scale laboratory flowslides. Geotechnique, 47: 915-932. http://cat.inist.fr/?aModele $=$ afficheN\&cpsidt $=2085$ 843

10. Iverson, 1997. The physics of debris flows. Rev. Geophys., $\quad 35$ : 245-296. http://direct.bl.uk/bld/PlaceOrder.do?UIN=030275 184\&ETOC $=$ RN $\&$ from $=$ searchengine

11. Armanini, A., H. Capart, L. Fraccarollo and M. Larcher, 2005. Rheological stratification in experimental free surface flows of granular liquid mixture. J. Fluid Mech., 532: 269-319. http://cat.inist.fr/?aModele $=$ afficheN\&cpsidt $=1689$ 3301
12. Armanini, A. and C. Gregoretti, 2005. Incipient sediment motion at high slopes in uniform flow condition. Water Resour. Res., 41: W12431.1-W12431.8. http://cat.inist.fr/?aModele $=$ afficheN\&cpsidt $=17444774$

13. Okada, Y. and H. Ochiai, 2008. Flow characteristics of 2-phase granular mass flows from model flume tests. Eng. Geol., 97: 1-14. http://cat.inist.fr/?aModele $=$ afficheN\&cpsidt $=2016$ 6349

14. Hutchinson, J.N., 1986. A sliding consolidation model for flow-slides. Can. Geotech. J., 23: 115-126. DOI: $10.1139 / \mathrm{t} 86-021$

15. Sivathayalan, S. and Y.P. Vaid, 2002. Influence of generalized initial state and principal stress rotation on the undrained response of sands. Can. Geotech. J., 39: 63-76.

http://cat.inist.fr/?aModele $=$ afficheN\&cpsidt $=1358$ 9430 